\title{
Pit viper envenomation in pediatric dogs: 5 cases
}

\author{
Carl Southern ${ }^{1}$, Ashley Allen-Durrance ${ }^{1}$, and Michael Schaer ${ }^{1}$ \\ ${ }^{1}$ University of Florida
}

April 8, 2021

\begin{abstract}
The objective of this case series is to describe the diagnosis, therapeutic intervention, and outcome of pit viper envenomation in five pediatric dogs. All five puppies survived to discharge, with no known complications from their envenomation or antivenom administration.
\end{abstract}

\section{Introduction}

Snakebite envenomation is a common medical emergency in several regions of the United States. North central Florida is home to several indigenous pit vipers including the eastern diamondback rattlesnake (Crotalus adamanteus), the water moccasin (Agkistrodon piscivorus), timber rattlesnake (Crotalus horridus ), and the pygmy rattlesnake (Sistrurus miliarius ). ${ }^{1}$ Most of the canine veterinary literature describes snakebite envenomation adults, excluding its effect or outcome on pediatrics.

Many dogs free roam leading to several unwitnessed bites. Therefore, the attending clinician often needs to make the diagnosis based on physical examination and supporting characteristic effects of envenomation including coagulopathy, hemolysis, neurological signs, hypotension, pain, and soft tissue damage. Clinical signs vary according to the snake involved, amount of venom delivered, venom components in the particular snake, and previous comorbidities of the victim. Except for the pygmy rattlesnake that causes severe pain at the bite site and occasional thrombocytopenia, the remaining pit vipers have venom causing various combinations of hemolysis, vasculotoxicity, tissue toxicity, coagulopathy, and rhabdomyolysis. Cardiotoxicity and neurotoxicity are additional features of eastern diamondback rattlesnake venom while some timber rattlesnakes have potent neurotoxicity. ${ }^{2}$

Limited evidence-based data exists to guide medical management of pit viper envenomation in children, and no pediatric guidelines exist in veterinary medicine. Pit viper envenomation in children was historically accompanied by an increased concern for grave consequences due to smaller patient size, thus theoretically exposing the victim to a higher concentration of venom per kilogram and potentially more severe consequences from the venom compared to adults. ${ }^{3}$ Recent literature in human medicine advocates for judicious use of antivenom based on systemic involvement (coagulopathy, shock, neurological signs, gastrointestinal signs, etc.) with infrequent fasciotomies reserved for management of compartment syndrome. ${ }^{4,5}$ Although variable, antivenom protocols in children recommend initial control of systemic signs with 4 to 18 (mean 7.7) vials of $\mathrm{F}(\mathrm{ab})$ antivenom with subsequent maintenance therapy of 2 vials every 6 hours. ${ }^{6}$ Hospitalization ranges from one to eight days (average 2 days), use of empirical antimicrobial therapy is discouraged, and outcome is often favorable. ${ }^{5,7,8}$

The objectives of this case series are to describe pit viper envenomation in five pediatric dogs, which has not been previously reported, and to show that treatment conforms to standard treatment recommended for mature dogs.

\section{Case History}




\section{Case 1}

A 14 week-old, $10.8 \mathrm{~kg}$ male intact American Pit Bull Terrier was evaluated for suspect pit viper envenomation. The puppy was unsupervised outside for two hours and found limping on his left hindlimb with two bleeding punctures over his fourth digit. Physical examination revealed left pelvic limb weight-bearing lameness with hemorrhagic lymphedema around two punctures on the left hind paw. The mentation and vitals were normal. A pain score ${ }^{*}$ of $1 / 4$ was assigned. Clinicopathologic abnormalities included: mild hyponatremia (140 mmol/L, reference range $146-151 \mathrm{mmol} / \mathrm{L})$, mild hypochloremia $(105 \mathrm{mmol} / \mathrm{L}$, reference range 108.5-116 mmol/L), mild anemia [packed cell volume (PCV) 32\%, reference range 33-55\%] without hemolysis, and moderate hypoproteinemia [total solids (TS): $48 \mathrm{~g} / \mathrm{L}$ (reference range 65-80 g/L); $4.8 \mathrm{~g} / \mathrm{dL}$ (reference $6.5-8 \mathrm{~g} / \mathrm{dL}$ ]. The activated clotting time (ACT) was normal (96 seconds (s); reference range 80-120 s). A snakebite severity score $(\mathrm{SSS})^{9}$ was $1 / 20$. One vial of $\mathrm{F}(\mathrm{ab})_{2}$ antivenom $^{\S}$ was diluted in $60 \mathrm{~mL} 0.9 \%$ saline and administered intravenously (IV) over an hour. Six hours later, the SSS was $2 / 20$. The puppy was maintained on IV lactated Ringer's solution (LRS) ${ }^{\mathbb{I}}$ at $4 \mathrm{~mL} / \mathrm{kg} / \mathrm{hr}$ and methadone ${ }^{* *}(0.25 \mathrm{mg} / \mathrm{kg}$ IV) if pain scores exceeded 1.5/4. No progression of envenomation or adverse reactions to antivenom occurred and the puppy was discharged 20 hours later.

\section{Case 2}

An 11 week-old, $7.4 \mathrm{~kg}$ female intact mixed breed dog was presented for suspected pit viper envenomation. While outside, the puppy cried out, became lame on the left forelimb, and was evaluated at an emergency hospital within 40 minutes. The temperature, heart and respiratory rates were 390C (102.30F), 280 beats/min, and 80 breaths/min, respectively. The puppy was laterally recumbent, obtunded, and had weak pulses despite a systolic blood pressure of $150 \mathrm{~mm} \mathrm{Hg}$. Severe swelling with two actively bleeding puncture wounds and ecchymoses were found on the left shoulder. The pain score ${ }^{*}$ was $4 / 4$. Clinicopathologic abnormalities included: mild hyperlactatemia (2.5 mmol/L, reference range $0.4-1.5 \mathrm{mmol} / \mathrm{L})$, anemia (PCV 27\%, reference range 33-55\%), severe thrombocytopenia (0-1 platelet/HPF with no clumping, reference range $>10 / \mathrm{HPF}$ ), and hypocoagulability (ACT $208 \mathrm{~s}$, reference range 80-120 s). The SSS was $10 / 20$. Two $15 \mathrm{~mL}(2 \mathrm{~mL} / \mathrm{kg}$ ) IV boluses of hypertonic saline ${ }^{\S}$ were administered followed by a $20 \mathrm{~mL} / \mathrm{kg}$ IV bolus then $3 \mathrm{~mL} / \mathrm{kg} / \mathrm{hr}$ IV LRS ${ }^{\mathbb{I}}$. One vial of $\mathrm{F}(\mathrm{ab})_{2}$ antivenom ${ }^{\S}$ was diluted in $60 \mathrm{~mL} 0.9 \%$ saline and administered IV over 20 minutes. An hour later, a repeat ACT was $>999 \mathrm{~s}$ (reference range 80-120s) and the SSS increased to $12 / 20$. Two additional vials of diluted $\mathrm{F}(\mathrm{ab})_{2}$ antivenom $^{\S}$ were administered IV over an hour. Three hours post-presentation, the SSS remained 10/20 and the ACT was $>999 \mathrm{~s}$ (reference range 80-120s); therefore, a fourth vial of diluted $\mathrm{F}(\mathrm{ab})_{2}$ antivenom $^{\S}$ was administered IV over an hour. The puppy remained tachycardic (230-270 beats $\left./ \mathrm{min}\right)$ and normotensive; $0.2 \mathrm{mg} / \mathrm{kg}$ methadone ${ }^{* *}$ IV was administered. Five hours post-presentation, the PCV/TS was $20 \%$ (reference range 33-55\%) and $34 \mathrm{~g} / \mathrm{L}$ (reference range $65-80 \mathrm{~g} / \mathrm{L} ; 3.4 \mathrm{~g} / \mathrm{dL}$, reference range 6.5-8 $\mathrm{g} / \mathrm{dL})$, respectively. Two additional vials of diluted $\mathrm{F}(\mathrm{ab})_{2}$ antivenom $^{\S}$ were administered. Approximately six hours post-presentation and after six vials of antivenom, the SSS decreased to 9/20 and mentation improved.

Thirteen hours post-presentation, the skin proximal to the bite site blackened. The puppy remained tachycardic (260 beats/min) with strong pulses, mucus membranes were pale, and non-localizing pain was evident on abdominal palpation. Repeat clinicopathologic parameters showed anemia [HCT 17\%, reference range 33$55 \%$; hemoglobin $55 \mathrm{~g} / \mathrm{L},(5.5 \mathrm{~g} / \mathrm{dL})$; reference range 140-260 g/L $(14-26 \mathrm{~g} / \mathrm{dL})]$, hypokalemia $(3.73 \mathrm{mmol} / \mathrm{L}$; reference range 3.98-4.41 mmol/L), hyponatremia (136.7 mmol/L; reference range $146-151 \mathrm{mmol} / \mathrm{L})$, and mild hyperlactatemia $(2.3 \mathrm{mmol} / \mathrm{L}$; reference range $(0.4-1.5 \mathrm{mmol} / \mathrm{L})$. Hypocoagulability resolved (ACT 74 $\mathrm{s}$; reference range 80-120 s) and the puppy was hypertensive at $170 \mathrm{~mm} \mathrm{Hg}$. An IV fentanyl constant rate infusion (CRI) at $2 \mu \mathrm{g} / \mathrm{kg} / \mathrm{hr}$ and ampicillin sulbactam $\mathbb{1} 30 \mathrm{mg} / \mathrm{kg}$ IV q8h was begun. Three vials of diluted $\mathrm{F}(\mathrm{ab})_{2}$ antivenom $^{\S}$ were administered IV as a CRI over 4 hours. The SSS 24 hours after admission was 6/20. The puppy began to eat, and the antibiotic was transitioned to amoxicillin/clavulanic acid ${ }^{* * *} 125 \mathrm{mg}(16.8$ $\mathrm{mg} / \mathrm{kg}$ ) PO q12h. Repeat PCV/TS were $13 \%$ (reference range 33-55\%) and $40 \mathrm{~g} / \mathrm{L}(4 \mathrm{~g} / \mathrm{dL}$ ) [reference range $65-80 \mathrm{~g} / \mathrm{L}(6.5-8 \mathrm{~g} / \mathrm{dL})]$, respectively. A packed red blood cell transfusion $(15.4 \mathrm{~mL} / \mathrm{kg})$ was administered over four hours. Two hours post-transfusion the PCV/TS were $23 \%$ (reference range 33-55\%) and $42 \mathrm{~g} / \mathrm{L}$ $(4.2 \mathrm{~g} / \mathrm{dL})$ [(reference range $65-80 \mathrm{~g} / \mathrm{L}(6.5-8 \mathrm{~g} / \mathrm{dL})]$, respectively. Fentanyl CRI was discontinued and tra- 
madol ${ }^{\S \S}$ was started at $25 \mathrm{mg}(3.4 \mathrm{mg} / \mathrm{kg}) \mathrm{PO}$ q12h. The puppy received one 45 -minute hyperbaric oxygen chamber treatment prior to discharge. By Day 4, the bite wound had well demarcated margins, but did not progress to sloughing.

\section{Case 3}

A 15 week-old, $9.1 \mathrm{~kg}$ female intact Golden Retriever puppy was examined within 30 minutes of suspected pit viper envenomation after being found outside with a left swollen muzzle and two puncture wounds two centimeters apart. Aside from moderate left-sided facial swelling, the physical examination was unremarkable. Vitals were normal and the pain score* was $0 / 4$. Abnormal clinicopathologic parameters included mild hypoproteinemia [TS $50 \mathrm{~g} / \mathrm{L}(5 \mathrm{~g} / \mathrm{dL})$, reference range $65-80 \mathrm{~g} / \mathrm{L} 6.5-8 \mathrm{~g} / \mathrm{dL})$ ] with slight hemolysis and hypocoagulability (ACT $>999 \mathrm{~s}$; reference range 80-120s). The SSS was $6 / 20$ and one vial of diluted $\mathrm{F}(\mathrm{ab})_{2}$ antivenom $^{\S}$ was administered IV over four hours, followed by IV LRS $\mathbb{1}$ at $3 \mathrm{~mL} / \mathrm{kg} / \mathrm{hr}$. Six hours postpresentation, the ACT remained too high to read and the SSS was 6/20. A second vial of diluted $\mathrm{F}(\mathrm{ab})_{2}$ antivenom $^{\S}$ was administered IV over four hours. The puppy was hospitalized overnight where coagulopathy resolved and clinical improvement occurred with lower SSS values of 2/20 and 1/20 at 13 hours and 25 hours after admission, respectively. By day two, the puppy was clinically stable and discharged.

\section{Case 4}

A 12 week-old, $4.3 \mathrm{~kg}$ male intact Beagle presented one hour after a witnessed pygmy rattlesnake bite to the muzzle. There was a noticeable swelling localized to the muzzle that was sensitive to touch and two visible bite wounds ventral to the nares. Vitals were normal. Abnormal clinicopathologic parameters included mild hyponatremia (140.5 mmol/L; reference range $146-151 \mathrm{mmol} / \mathrm{L}$ ). The PCV and TS were $46 \%$ (reference range $33-55 \%)$ and $58 \mathrm{~g} / \mathrm{L}(5.8 \mathrm{~g} / \mathrm{dL})$ [(reference range $65-80 \mathrm{~g} / \mathrm{L}(6.5-8 \mathrm{~g} / \mathrm{dL})]$ with no hemolysis, respectively; and, the ACT was $81 \mathrm{~s}$ (reference range 80-120 s). The puppy's initial SSS was 2/20. One vial of F(ab) 2 antivenom $^{\S}$ was diluted in $100 \mathrm{~mL} 0.9 \%$ saline with $25 \mathrm{~mL}$ administered as a bolus, then $75 \mathrm{~mL}$ administered as a CRI over six hours. The puppy was maintained on IV LRS $\mathbb{I}$ at $3 \mathrm{~mL} / \mathrm{kg} / \mathrm{hr}$. Six hours later, the ACT was normal and SSS was $2 / 20$. The facial swelling spread to the face, lips, and eyelids. The puppy was discharged after 24 hours.

\section{Case 5}

A 20 week-old, $15.2 \mathrm{~kg}$ female intact Australian Blue Heeler was presented after an unwitnessed bite $30 \mathrm{mi}$ nutes prior to arrival. Physical examination revealed moderate right-sided muzzle swelling with two bleeding puncture wounds ventral to the right eye. The puppy appeared dull, nauseous and had a tense abdomen. The puppy's pain score ${ }^{*}$ was $2 / 4$; and vitals were normal. Abnormal clinicopathologic parameters included mild hyperlactatemia $(2.4 \mathrm{mmol} / \mathrm{L}$; reference range $0.4-1.5 \mathrm{mmol} / \mathrm{L})$ and hemolyzed serum with a normal PCV and TS, 53\% (reference range 33-55\%) and $78 \mathrm{~g} / \mathrm{L}(7.8 \mathrm{~g} / \mathrm{dL}$ ) [reference range 65-80 g/L (6.5-8.0 $\mathrm{g} / \mathrm{dL}$ )], respectively. Blood smear revealed echinocytosis and mild thrombocytopenia (mean 9 platelets per HPF; reference range $>10$ platelets/HPF). Systolic blood pressure was $90 \mathrm{~mm} \mathrm{Hg}$, and the ACT was 58 seconds (reference range 80-120 s). The SSS was 5/20. The puppy was administered one vial of diluted $\mathrm{F}(\mathrm{ab})_{2}$ antivenom $^{\S}$ IV over 30 minutes and a second vial over the next 2 hours along with LRS $\mathbb{I}$ IV fluids at $3 \mathrm{~mL} / \mathrm{kg} / \mathrm{hr}$. Six hours later, the SSS remained 5/20. The puppy was hospitalized overnight for monitoring. The facial swelling continued to spread, but the pain resolved. By day two, the appetite was hearty, the SSS had decreased to $2 / 20$, and the puppy was discharged.

\section{Discussion}

North central Florida is a unique geographic area home to five indigenous venomous pit vipers including water moccasins, and eastern diamondback, timber and pygmy rattlesnakes. The amount of venom injected varies according to the species, snake size, time lapse since the last venom delivery, and degree of threat sensed prior to venom delivery. ${ }^{10-12}$ Adult dogs might pose more of a threat to the snake compared to the playful and naive nature of puppies which would cause the snake to release more venom into the adult victim. ${ }^{10}$ This might be a contributing reason to explain why all five puppies in this series survived. 
All five of the puppies were taken to the emergency hospital within a two-hour period following their likely snake encounter. Four of these were fortunate to maintain stable vital signs upon presentation. Case two was on the threshold of decompensating, but readily stabilized with emergency treatment. In envenomated children, their small size has traditionally been thought to predispose them to a greater amount of venom per square meter area, thus exposing more cells to the adverse effects of the venom. ${ }^{13,14}$ In Parish's study dating as far back as 1965, the majority of children did well so long as they received antivenom. ${ }^{13}$ In LoVecchio's study of 66 envenomated children over a 10-year period, $38 \%$ of children developed a hypersensitivity to whole IgG antivenom and there were five cases of morbidity, but all survived. ${ }^{14}$ These reports of increased rather than decreased survival is likely due to the availability of antivenom and its use in children during the 1960's and after. The same guarded prognosis was assumed with this young canine population, but all puppies in this report survived as well with timely antivenom and medical management.

These five puppies are the first cluster of canine pediatric snake bite victims, aged 11 to 20 weeks old, in the United States to be described. The clinical signs in this particular group were similar to those seen in many adult dogs in the same region. ${ }^{15,16}$ Two of the four had prolonged activated clotting times, with bleeding restricted to the bite site. The ACT was selected to monitor coagulopathy because of the small amount of blood required for this test, its relative low cost, proximity of the machine to the emergency room, and its proven clinical benefits as a point-of-care test when managing snake bite victims with coagulopathies. ${ }^{17}$

Three of the five puppies were bitten in the face while two were bitten in the limbs which is similar to that seen in adult dogs. ${ }^{15}$ The snake bite severity scores ranged from 1 to 10 with all values reverting to minor status by day two following treatment.

The amount of antivenom administered to each puppy paralleled its SSS whereby those with scores $<2$ receiving 1-2 vials, and the most severely affected puppy (case two) with a presenting score of 10 receiving proportionally more antivenom (nine total vials). None of the puppies in this case series developed a hypersensitivity reaction to the $\mathrm{F}(\mathrm{ab})_{2}$ antivenom $^{\S}$. In children, hypersensitivity reactions to equine-derived $\operatorname{IgG}$ antivenom is common $(38 \%)^{14}$, while less common $(2.8 \%)^{7}$ when administered ovine-derived $\mathrm{F}($ ab) antivenom. As this is a small case series, it is likely that equine derived $\mathrm{F}(\mathrm{ab})_{2}$ antivenom has the potential to cause hypersensitivity reactions in puppies, similar to adult dogs. ${ }^{15}$

Fluid overload in children weighing less than $10 \mathrm{~kg}$ and those with physiologic concerns for fluid overload, such as congestive heart failure, chronic lung disease, and renal insufficiency is a concern in human medicine when multiple doses of antivenom are administered as their protocols typically dilute antivenom in $250 \mathrm{~mL} 0.9 \%$ saline. ${ }^{7}$ Puppies in this study ranged from 4.3 to 15.2 kilograms, and the same risk for fluid overload should be considered when treating pediatric dogs requiring multiple doses of antivenom. In this series, antivenom was diluted in 50 to $100 \mathrm{~mL} 0.9 \%$ saline at the clinician's discretion, and no reported complications from fluid overload occurred.

The small number of puppies included in this case series limits statistical analysis to determine prognostic factors. In addition, due to the retrospective nature of this case series and medical record system at the author's institution, cases were obtained by searching invoice items for pit viper antivenom and age of six months or less in dogs. As such, puppies presenting to the emergency room with a snake bite, but did not receive antivenom, due to lack of clinical need or owner financial restrictions, would have been overlooked in data collection. Therefore, prospective studies to enroll all pediatric dogs with a witnessed or suspected pit viper envenomation are warranted to determine morbidity and mortality.

\section{Footnotes}

* Colorado State University Acute Pain Scale, Fort Collins, CO.

$\S$ VenomVetß, MT Venom, LLC, Canoga Park, CA.

$0.9 \%$ sodium chloride, Abbott Laboratories, Irving, TX.

$\mathbb{I}$ Lactated Ringer's Solution, Baxter Laboratories, Deerfield, IL. 
** Methadone hydrochloride, Mallinckrodt Inc, Hazelwood, MO.

$\S \S$ Vet One, MWI Animal Health, Boise, ID.

Fentanyl citrate, Akorn, Inc, Lake Forest, IL.

II Unasyn ${ }^{\circledR}$, Pfizer, New York, NY.

${ }^{* * *}$ Clavamox ${ }^{\circledR}$, Zoetis Inc, Kalamazoo, MI.

$\S \S \S$ Tramadol 50 mg tabs, Jannssen Ortho LLC, Puerto Rico.

\section{References}

1. Campbell JA, Lamar WW. Pit Vipers, Family Viperidae, Rattlesnakes. In: Campbell JA, Lamar WW, editors. The Venomous Reptiles of the Western Hemisphere. Vol 1. Comstock Pub. Associates; 2004, pp 477-616

2. Gilliam LL, Brunker J. North American Snake Envenomation in the Dog and Cat. Vet Clin North Am Small Anim Pract . 2011;41(6):1239-1259.

3. Avila-Agüero ML, Valverde K, Gutiérrez J, París MM, Faingezicht I. Venomous snakebites in children and adolescents: a 12-year retrospective review. J Venom Anim Toxins . 2001;7(1):69-84.

4. Weber RA, White RR. Crotalidae envenomation in children. Ann Plast Surg . 1993;31(2):141-145.

5. Correa JA, Fallon SC, Cruz AT, et al. Management of pediatric snake bites: Are we doing too much? $J$ Pediatr Surg . 2014;49(6):1009-1015.

6. Offerman SR, Bush SP, Moynihan JA, Clark RF. Crotaline Fab Antivenom for the treatment of children with rattlesnake envenomation.Pediatrics . 2002;110(5):968-971.

7. Goto CS, Feng S-Y. Crotalidae Polyvalent Immune Fab for the treatment of pediatric crotaline envenomation. Pediatr Emerg Care . 2009;25(4):273-279.

8. Campbell BT, Corsi JM, Boneti C, Jackson RJ, Smith SD, Kokoska ER. Pediatric snakebites: lessons learned from 114 cases. J Pediatr Surg . 2008;43(7):1338-1341.

9. Dart RC, Hurlbut KM, Garcia R, Boren J. Validation of a severity score for the assessment of crotalid snakebite. Ann Emerg Med . 1996;27(3):321-326.

10. Hayes WK, Lavín-Murcio P, Kardong KV. Northern Pacific Rattlesnakes (Crotalus viridis oreganus) meter venom when feeding on prey of different sizes. Copeia . 1995;1995(2):337-343.

11. Hayes WK. Effects of hunger on striking, prey-handling, and venom expenditure of prairie rattlesnakes (Crotalus v. viridis).Herpetologica . 1993;49(3):305-310.

12. Hayes WK, Hayes DM. Stimuli Influencing the release and aim of predatory strikes of the northern pacific rattlesnake (Crotalus viridis oreganus). Northwest Nat . 1993;74(1):1-9.

13. Parrish HM, Silberg SL, Goldner JC. Snakebite a pediatric problem. Clin Pediatr (Phila) . 1965;4:237-241.

14. LoVecchio F, DeBus DM. Snakebite envenomation in children: a 10-year retrospective review. Wilderness Environ Med . 2001;12(3):184-189.

15. Armentano RA, Schaer M. Overview and controversies in the medical management of pit viper envenomation in the dog. J Vet Emerg Crit Care San Antonio Tex 2001 . 2011;21(5):461-470.

16. Schaer M, Buckley GJ, Conner BJ, et al. Severe pit viper envenomation with extended clinical signs and treatment complications in a dog. J Am Anim Hosp Assoc . 2015;51(5):329-337.

17. Schaer M. Persistent pit viper envenomation in three dogs. Toxicon Off J Int Soc Toxinology . 2019;166:8387. 